\title{
Cost-Benefit Analysis and Basic Needs
}

\section{Mike Veitch}

During the past few years, considerable attention has been devoted to re-examining the fundamental objectives of development. The impetus for this has come from the realisation that the emphasis on economic growth, which dominated development strategy during the 1950 s and $1960 \mathrm{~s}$, has made little if any impact on the welfare of the poorest. As a result there has been a shift away from this preoccupation with growth towards a greater concern with the distribution of income. This shift in emphasis has recently been taken further with the realisation that, for hundreds of millions, development should mean the satisfaction of their basic needs.

The past decade has also witnessed major innovations in cost-benefit analysis (CBA). In a book published in 1967, Marglin examined ways in which CBA might be made to reflect national cbjectives. In the following year Little and Mirrlees produced the first fully comprehensive framework which took CBA out of the narrow confines of its traditional private standpoint, and showed how it might assist in attaining wider national goals. Since then further modifications have been made to the techniques so that at present the methodology comprises a three-tier system of private, economic and social appraisal.

This paper considers the extent to which the techniques, as they stand at present, meet the requirements generated by the increased emphasis on income distribution and, in particular, the satisfaction of basic needs. It is suggested that, when looked at in this light, there are still certain shortcomings in the basic methodology; according!y a modification is proposed.

\section{Planning for basic needs}

During the 1950 s and early 1960 s, the principal emphasis in developmental strategy was planning for growth of national income, and income per capita was taken as the most appropriate measure of development. The reasons for such a singleminded approach need not be elaborated here. Whatever the overall merits of such a policy, there can be no doubt that it was successful in so $\mathrm{far}$ as national income increased at an unprecedented rate in almost all countries during this period. Even when account is taken of population growth, the result was still a higher rate of growth of per capita national income than ever before.

By the early 1970 s, however, increased dissatisfaction was being expressed with national income growth as a measure of, or even as a means to, improved welfare. This dissatisfaction manifested itself in two ways. First, the concept of national income as an adequate measure of development was questioned. Ignoring for the moment matters of distribution, it is not self-evident that national product, which measures the output of goods and services, should be a satisfactory measure of the general welfare of the population. This line of thought led to research into alternative measures, frequently referred to as social indicators of development; examples are measures of nutrition, standards of housing, and levels of health and education (for example, Adelman and Morris 1973 and Drewnowski 1974).

Second, it became increasingly clear that the fruits of growth were not being distributed in an equitable manner. Advocates of growth had expected, or at least hoped, that the benefits of increased growth would ultimately 'trickle down' to the poorest, although the exact way in which this would happen was never clearly spelt out. But by the 1970 s it was clear that, in spite of considerable recorded increases in income per capita, income distribution had not necessarily improved; indeed, in some countries it appeared to have worsened, although the statistical evidence was not always too precise. In a recent survey, Ahluwalia noted that, whilst there was not necessarily a conflict between growth and development, it was clear that rapid growth did not of itself bring about more equitable distribution (Ahluwalia in Chenery et al 1974). 'Trickle down', if it existed, was a long time coming.

More recently there has been further progress in the design of development planning strategies involving both the use of social indicators and an increased concern with distribution. The result is what has been called a strategy of 'planning to satisfy basic needs'. This goes beyond an examination of the extent of poverty, and looks at its causes and characteristics. Such an approach is essential if policics for alleviating poverty are to be designed and implemented.

The IBRD/IDS study on income distribution referred to earlier (Chenery et al 1974), goes far beyond stating a general concern with the failure of growth-oriented strategies to bring about 
development. It includes estimates of the numbers of persons living below a particular poverty line and, drawing on the evidence of another study (Chenery and Syrquin 1975), goes on to examine the principal characteristics of poverty, to identify potential target groups, and to suggest policy recommendations. Some of the latter are of an institutional nature, such as land distribution and the reform of fiscal systems; others relate to the need for improved health services and housing for instance.

Research of a similar nature has also been pursued by the ILO. Not unnaturally, the latter has tended to place greater emphasis on employment generation as the prime need to be satisfied. Between 1970 and 1976 the ILO carried out a series of country-wide studies into 'Growth, Equity and Employment', the main findings of which are summarised in the report prepared for the 1976 World Employment Conference (ILO 1976). Like the IBRD/IDS study, the report concentrates on problems of poverty, but goes on to discuss strategies designed to meet basic needs.

Neither of these studies can be regarded as a detailed blueprint for planning, if only because they both take an overall view rather than examining the specific needs of individual countries. Their purpose is to redirect planning efforts into a new direction which, it is hoped, will make a greater impact on development in its widest sense than have past strategies. But if planning for basic needs is to be successful, the basic needs themselves must first be defined. This can be done in either relative or absolute terms and, while some guidance on this appears in both reports, such a definition can properly be made only at the national level. Once basic needs have been defined, the next step is to identify those groups who fail to reach the prescribed levels. ${ }^{1}$

This paper does not attempt to consider in detail exactly what constitutes an individual's basic needs. For the discussion which follows, it will suffice to divide basic needs into two categories (see ILO 1976:32):

1. Employment, including self-employment and family employment, yielding an income sufficient for the household to make at least all the private purchases necessary for meeting its basic individual needs, such as food and clothing, as well as any communal needs for which charges may be made;

\footnotetext{
1 This is not necessarily the same as identifying those who fall below a particular poverty line as measured on a per capita income basis. It is quite possible, for example, for low income families to be adequately housed, just as families with relatively high incomes may be found living in shanty towns.
}

2. Services including water supply, sewerage, health, education and transport which are necessary for meeting basic communal needs.

Both the ILO and the IBRD/IDS studies suggest a number of policies which might form part of an overall strategy to provide for basic needs. In addition to domestic policies, there is no doubt that some of an international nature are also required (see Tinbergen 1976). It is not intended in this paper to discuss the relative merits of the various policies which have been proposed. What is relevant, however, is the fact that the implementation of any policy will generate major demands for additional scarce resources to meet these needs. Since CBA is a methodology designed to assist decision makers in making an optimum allocation of available resources among competing needs, it will be useful to discuss the extent to which the current techniques of CBA successfully complement a basic needs strategy.

\section{Cost-benefit analysis within a basic needs framework}

The improvements made to the methodology of CBA over the past decade have been aimed at turning it into a tool which can assist governments towards more closely attaining national development goals. Previously projects were appraised, and decisions regarding their implementation were taken, from a private standpoint. In most cases this meant that profit maximisation was taken as the project objective, although for certain sectors, such as transport or water resources, alternative objectives might be substituted. National objectives were seldom explicitly taken into account when calculating the project's net present value or rate of return.

Two national objectives have been recognised as particularly appropriate for project appraisal purposes. The first is sometimes called the efficiency criterion, in which the project's contribution to profits is replaced by its contribution to national income. This is effected by including externalities, wherever possible, in the project cash flow, and by revaluing the entire cash flow at accounting instead of market prices. This produces an economic analysis.

The second objective relates to income distribution. This requires that project beneficiaries be identified according to their income levels. The beneficiaries are those who receive the additional income generated by the project in the form of extra wages, returns to capital invested, increased farmers' incomes, and so forth (those who suffer additional costs should similarly be identified). The additional income is then revalued by the 
application of a special set of weights which are intended to mirror, as accurately as possible, government objectives concerning income distribution. At the same time, adjustments are made to take account of government priorities between savings and consumption, and the spread of benefits over time. The application of the appropriate social parameters to economic accounting prices such as the shadow wage rate transforms them into a set of social accounting prices. Whilst in principle all accounting prices should adjust when the transition from an economic to a social appraisal is made, in practice changes are most likely on the input side of the cash flow.

This summary of recent developments in CBA should be viewed against the background of changing attitudes to development planning described above. It is interesting to note that the move towards incorporating national economic objectives within the framework of CBA has taken place at a time when disenchantment with over-reliance on economic growth was setting in. In this sense, the work of Marglin and of Little and Mirrlees, path-breaking though it was, came a decade later than it ought to have done. Regarding the application of social appraisal, it is fair to say that this is still at an experimental stage, despite the more recently published methodologies of Sen, Marglin and Dasgupta (1972) and of Squire and van der Tak (1975); the latter clarifies a number of issues raised earlier in Little and Mirrlees (1968 and 1974). Meanwhile, at the macro level, it was seen earlier that approaches to development planning have moved beyond merely considering the relationship between growth and distribution, towards planning for a basic needs strategy. The next task is to see to what extent CBA, in the present state of the art, is likely actively to assist in attaining such a strategy. For this purpose, it will be convenient to examine individual and communal needs separately.

The ILO study stresses the importance, as a basic need, of employment, including self-employment, at a level which provides sufficient income to enable households to purchase the various items of basic individual need such as food and clothing. The application of economic and social CBA is likely to assist this strategy, even though employment generation is not designated as an explicit objective. Since economic appraisal makes use of accounting prices, all project inputs and outputs will be re-valued at prices which reflect national opportunity costs and benefits. Thus scarce resources such as capital equipment will have high opportunity costs, particularly when they require scarce foreign exchange; this will be reflected in their accounting prices. By contrast, where there is an abundance of unskilled labour with a correspondingly low opportunity cost, the shadow wage rate will normally be well below the market wage. In this way, the application of economic CBA will encourage labour-intensive rather than capital-intensive modes of production.

Provided problems of correctly identifying project beneficiaries and of establishing an acceptable method of deriving income distribution weights can be overcome, the application of social CBA should heighten this effect. The lower the incomes of those who are employed by the project, or who otherwise receive the extra income generated, the greater will be the values of the distribution weights placed on their incremental consumption. This will tend to lower shadow wages and hence increase the project's net present value, which is in line with a basic needs strategy. Moreover the values taken by these weights are also influenced by the value of the 'elasticity of marginal utility', which does duty as a policy variable representing the extent of the government's commitment to income redistribution. A high value of the elasticity presupposes a strong commitment, and will widen the range of values which are taken by the distribution weights for a particular set of incomes, and hence give an even greater weight to incomes received by the poorest income groups. This also accords with a basic needs strategy. There is every reason to believe, therefore, that the application of social CBA will be of real assistance to a country which is trying to follow such a strategy, in so far as it will give encouragement to projects which will either directly generate more employment or will otherwise raise the incomes of the poorest, thus enabling them to purchase their basic individual needs.

Turning now to the provision of what were earlier termed basic communal needs, such as adequate health and education services, a somewhat different picture emerges. These services constitute the output or benefit of a project, and naturally their value should appear on the output side of the cash flow, in contrast to labour which is an input. It is not immediately obvious that economic or social appraisal will necessarily assist in directing such projects towards meeting social needs. To begin with, in many of these sectors there are severe, some would say insuperable, problems in quantifying and valuing the project benefits. If these cannot be resolved, then recourse must be made to cost-effectiveness analysis. 
But even if this hurdle can be cleared, another awaits. For the most part basic needs, and particularly those of a communal nature, are services; as such, they cannot be traded internationally. This raises problems of revaluing the project output at accounting prices, particularly with respect to the Little-Mirrlees/Squire-van der Tak methodology, since the numeraire is expressed in terms of border or world prices. The method requires that all project inputs and outputs are expressed in terms of the numeraire; for nontradeable services, however, there are no such world prices. Whilst recognising the importance of the problems raised here and above they will not be discussed further in this paper.

The implication of a basic needs strategy is that goods and services which satisfy the needs of the poor should, in some way, be valued more highly than equivalent items which improve the general standards of living of the rich. This suggests that, in an appraisal, such items should receive a special weight. However no attempt is made under existing procedures to do this. The only weights which are applied to output are economic accounting prices. These have a more general function, and may give preference to exportoriented output, or to the use of domestic rather than foreign resources, or to labour in preference to capital; but they do not distinguish between commodities consumed by different households. Neither do social accounting prices which, in any case, act primarily on the input side of the cash flow.

Furthermore the measure of project benefits which appears in the cash flow depends to a very great extent on the existing price structure, and hence on the existing distribution of income. This is just as true for sectors such as education, where the standard approach to measuring benefits is based on incremental earnings received (Blaug, 1970), as for projects whose output is sold on the market. Whilst economic accounting prices adjust the prices thrown up by the market, they do not make the adjustment in order to modify the effects of the existing distribution of income and hence of demand. There is no particular reason why a system of valuation based upon such a price structure should give encouragement to projects which aim to satisfy basic communal needs; on the contrary, it is quite possible that the opposite result would occur.

Placing special weights on output depending on the status of the consumer is analogous to the idea of merit-want goods or, possibly, non-merit goods. Economists have tended to shy away from the use of such concepts, although they have long been recognised in economic theory (Musgrave
1959: 13-14). The economist's ambivalence is well summed up by Marglin, who remarked that 'on Mondays, Wednesdays and Fridays I am thoroughly convinced of the merit-want objective, but on Tuesdays, Thursdays and Saturdays I am equally sure that the essence of human freedom is individual choice'. He goes on to say, however, that 'the choice of ignorance for one's children or an inadequate diet seems to stretch unreasonably the range of decisions for which an individual choice should apply' (Marglin 1967: 22). Although he does appear to have some sympathy with the idea, Marglin comes to the conclusion that most merit-want goods are covered by what he terms the 'group distribution objective', and the remainder open up potential areas of abuse. A further reason for this reluctance to make use of the merit good concept may stem from problems of definition; few would argue that milk for young children constituted a merit good or tobacco a non-merit good, but a hazy area lies in between.

There seems to be no obvious way by which CBA, as currently practised or proposed, can act as a specitic means of implementing a basic communal needs strategy. The application of accounting prices and distributional weights should give encouragement to employmentgenerating projects, but it will not necessarily direct resources towards projects which satisfy the communal needs of the poor rather than those which produce added comforts for the rich. $A$ priori, there is no particular reason why building houses, providing education and running transport services for the poor should be any more (or less) labour-intensive than providing these services for the rich.

The way out of this impasse may be to allow the same kind of adjustment to be made to the benefit or output side of a cost-benefit calculation as is made to the cost side if distribution weights are applied. Such weights would reflect not just the type of good or service which constituted the project output but, in addition, the intended beneficiaries. Thus, under such a system, a housing scheme which was intended to re-house persons previously dwelling in shanty towns would receive a higher rating than a more luxurious scheme, of approximately the same size, which would accommodate people who already had respectable housing. The actual values of the weights would reflect either the income levels of the beneficiaries or some alternative criterion such as the extent to which they were in need; in this example an appropriate measure might be a comparison of actual house space per household member, with an adjustment for 
quality, with a prescribed norm. The weights themselves might resemble the income distribution weights in the Squire-van der Tak system, and indeed the latter might even be used as proxies. The distinction as to whether a particular project was designed to serve the needs of the poor or improve living standards of the rich would, in many cases, be obvious from the location of the project. In other cases it might depend upon the precise nature of the commodity-for instance, adult literacy classes (which would benefit the poor) or improved facilities for higher education (which might be of greater advantage to the rich).

This is a resurrection of the argument that the provision of merit-want goods should be incorporated in CBA as an explicit objective. Marglin's first objection, that such items are already covered by the distribution objective, is only valid as regards employment generation; it does not give any precedence to projects the object of which is to satisfy basic communal needs. Of course the problem of defining merit goods remains, and this requires value judgements.
But there is no reason why these should be either more difficult than, or more contentious than, judgements which are needed for a social appraisal. Whatever the problems in making such judgements, it should be remembered that without them project appraisal is forced back to the position of an economic analysis in which equal weights are placed on incremental incomes, no matter what the income levels of the recipients. A step in the right direction is surely better than no step at all.

Naturally, certain theoretical developments remain to be worked out, and further research will be needed before merit goods can be incorporated in project appraisal in a suitably rigorous fashion. Similar developments are currently going on in the field of social appraisal. Once this has been accomplished, there would seem to be no reason why CBA should not, in this way, keep abreast of the changes which are currently taking place in working out new strategies for development planning. 